\title{
Correction to: Children's Mental Health, Deployment, Parental Mental Health, and Family Dynamics: Findings from the Millennium Cohort Family Study
}

Ernestine C. Briggs, Robert A. Murphy, Sherika N. Hill, Nida H. Corry, Valerie A. Stander, Angela M. Tunno, Jacqueline C. Pflieger, Sabrina M. Richardson, and John A. Fairbank

\section{Correction to:}

Chapter 8 in: J. E. Glick et al. (eds.), Parent-Child Separation, National Symposium on Family Issues 1, https://doi.org/10.1007/978-3-030-87759-0_8

This book was inadvertently published with the wrong affiliation of Dr. John A. Fairbank. The correct affiliation is

John A. Fairbank

VA Mid-Atlantic Mental Illness Research

Education and Clinical Center (VISN 6 MIRECC)

Durham VA Health Care System

Durham, NC, USA

This has now been amended throughout the book (COP, TOC) to the inclusion of right affiliation. 